Supporting Information

\title{
Drop-casting method to screen Ruddlesden-Popper perovskite formulations for use in solar cells
}

\author{
Chuantian Zuo ${ }^{\mathrm{ab}}$, Andrew D. Scully ${ }^{\mathrm{a}}$, and Mei Gao* \\ ${ }^{a}$ Flexible Electronics Laboratory, CSIRO Manufacturing, Clayton, VIC 3168, Australia \\ ${ }^{b}$ CAS Center for Excellence in Nanoscience, CAS Key Laboratory of Nanosystem and \\ Hierarchical Fabrication, National Center for Nanoscience and Technology, Beijing 100190, \\ China
}

*Email: Mei.Gao@csiro.au 


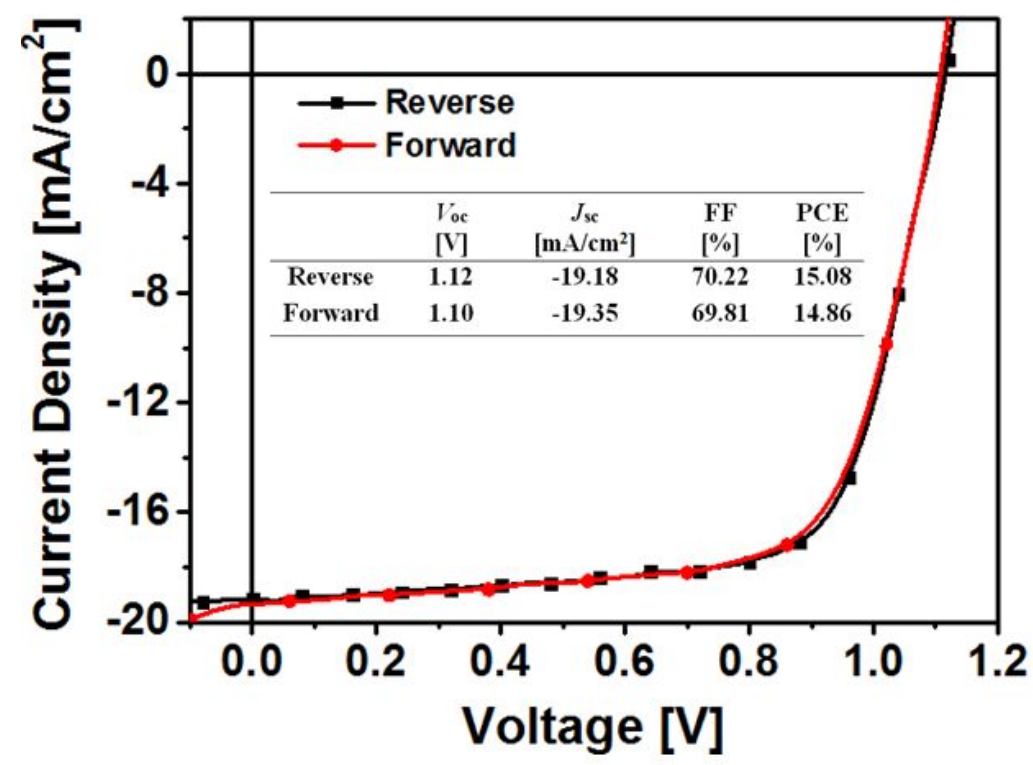

Figure S1. Reverse and forward scan $J-V$ curves for the 'champion' cell comprising a layer drop-cast using a solution of $\left(\mathrm{C}_{4} \mathrm{~A}\right)_{2} \mathrm{MA}_{4} \mathrm{~Pb}_{5} \mathrm{I}_{16}$ in DMF.

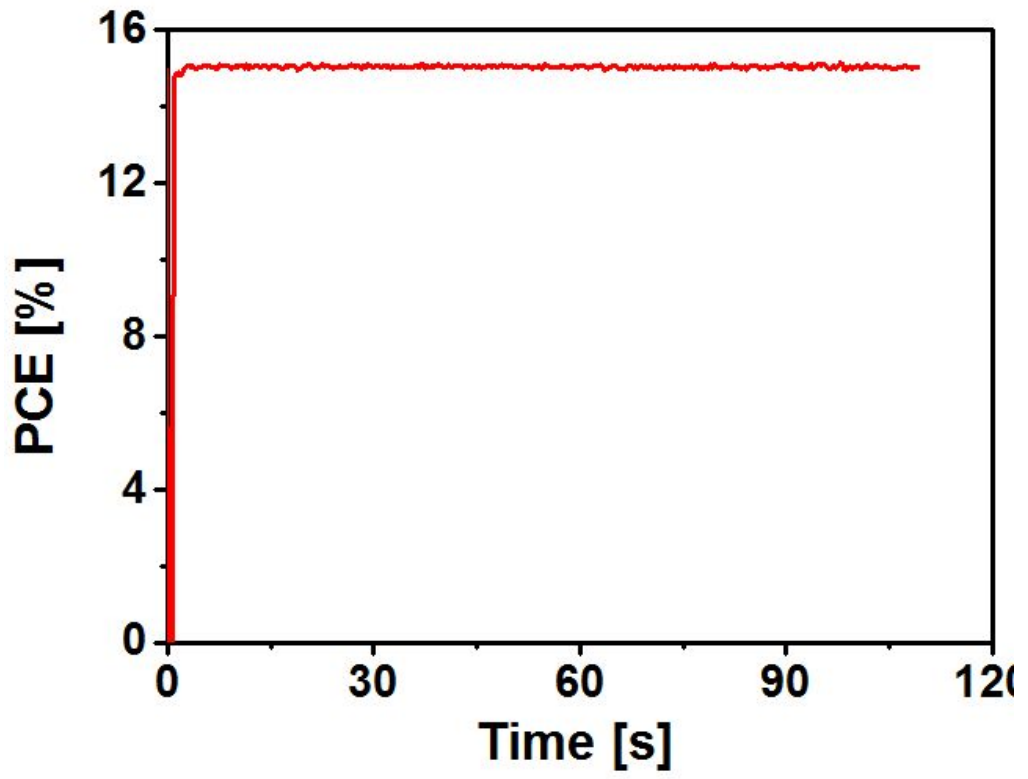

Figure S2. PCE for the 'champion' cell obtained using MPP tracking. 
$0 \mathrm{~s}$
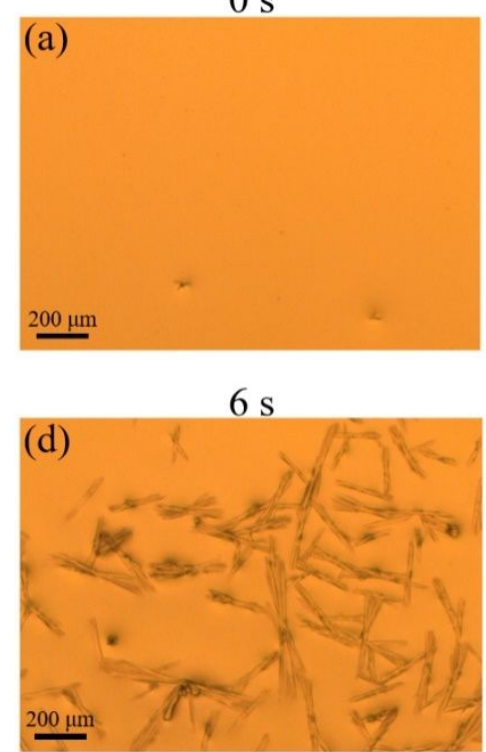

$2 \mathrm{~s}$

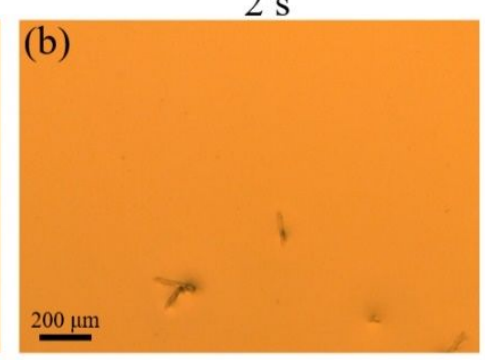

$10 \mathrm{~s}$

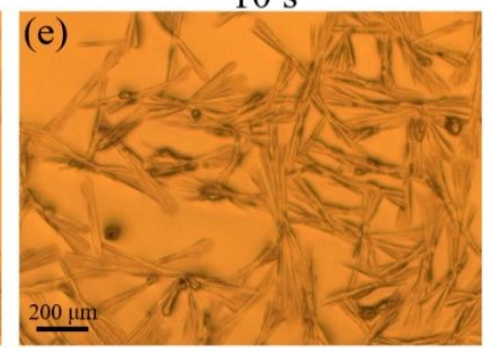

$4 \mathrm{~s}$

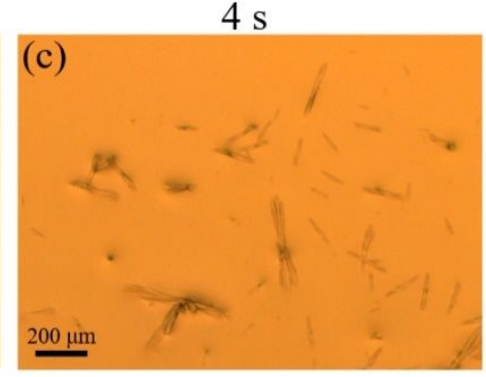

$15 \mathrm{~s}$

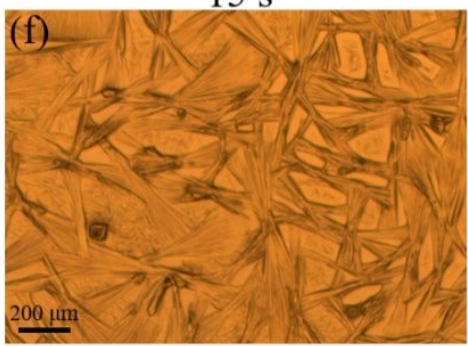

Figure S3. In-situ optical microscope images for $\mathrm{MAPbI}_{3}$ crystal growth process in the dropcast film on a glass substrate in air. The drop-cast film was prepared using a solution of $\mathrm{MAPbI}_{3}$ in DMF $(0.3 \mathrm{M})$. The wet film was placed under the microscope to observe the crystal growth. Substrate temperature: $60{ }^{\circ} \mathrm{C}$.

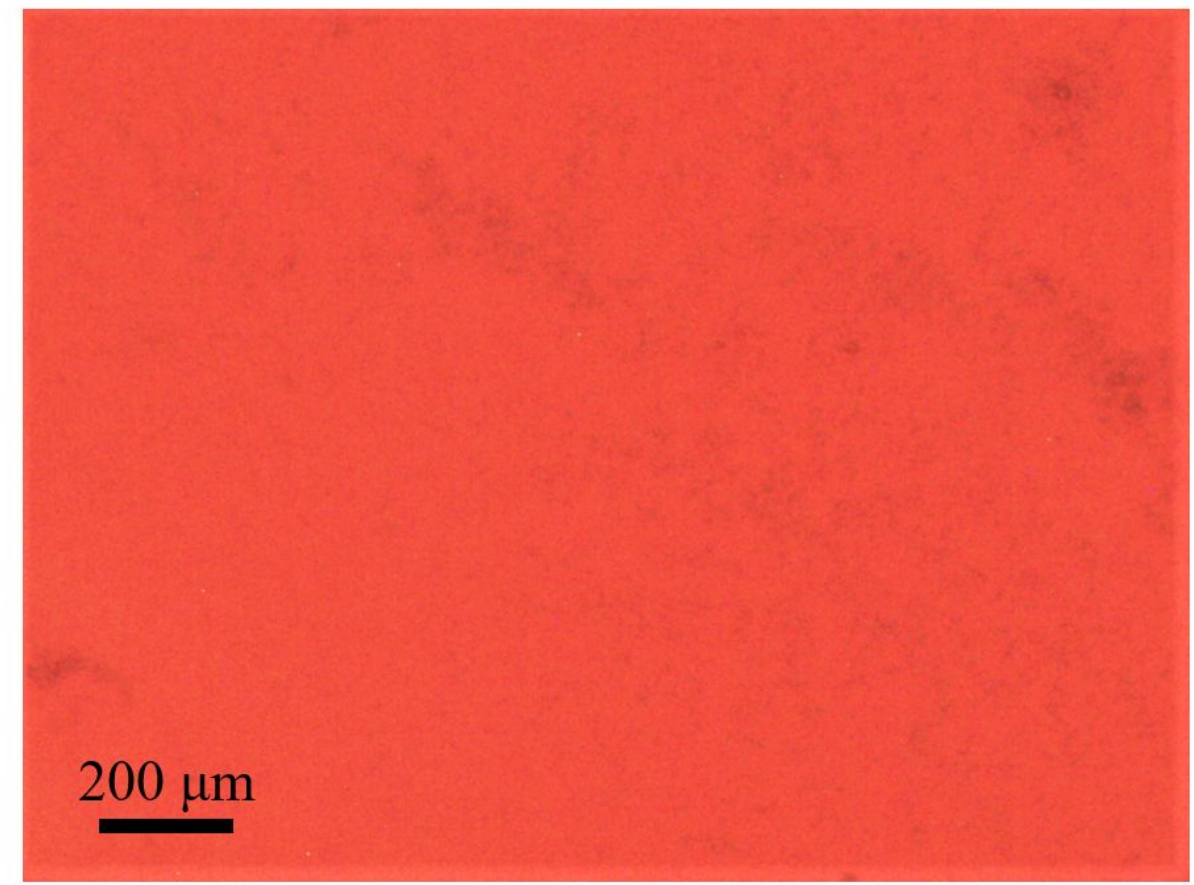

Figure S4. In situ optical microscope image of a film drop-cast using a solution of $\left(\mathrm{C}_{4} \mathrm{~A}\right)_{2} \mathrm{MA}_{4} \mathrm{~Pb}_{5} \mathrm{I}_{16}$ in DMF, showing grains that are too small to resolve using this technique. 

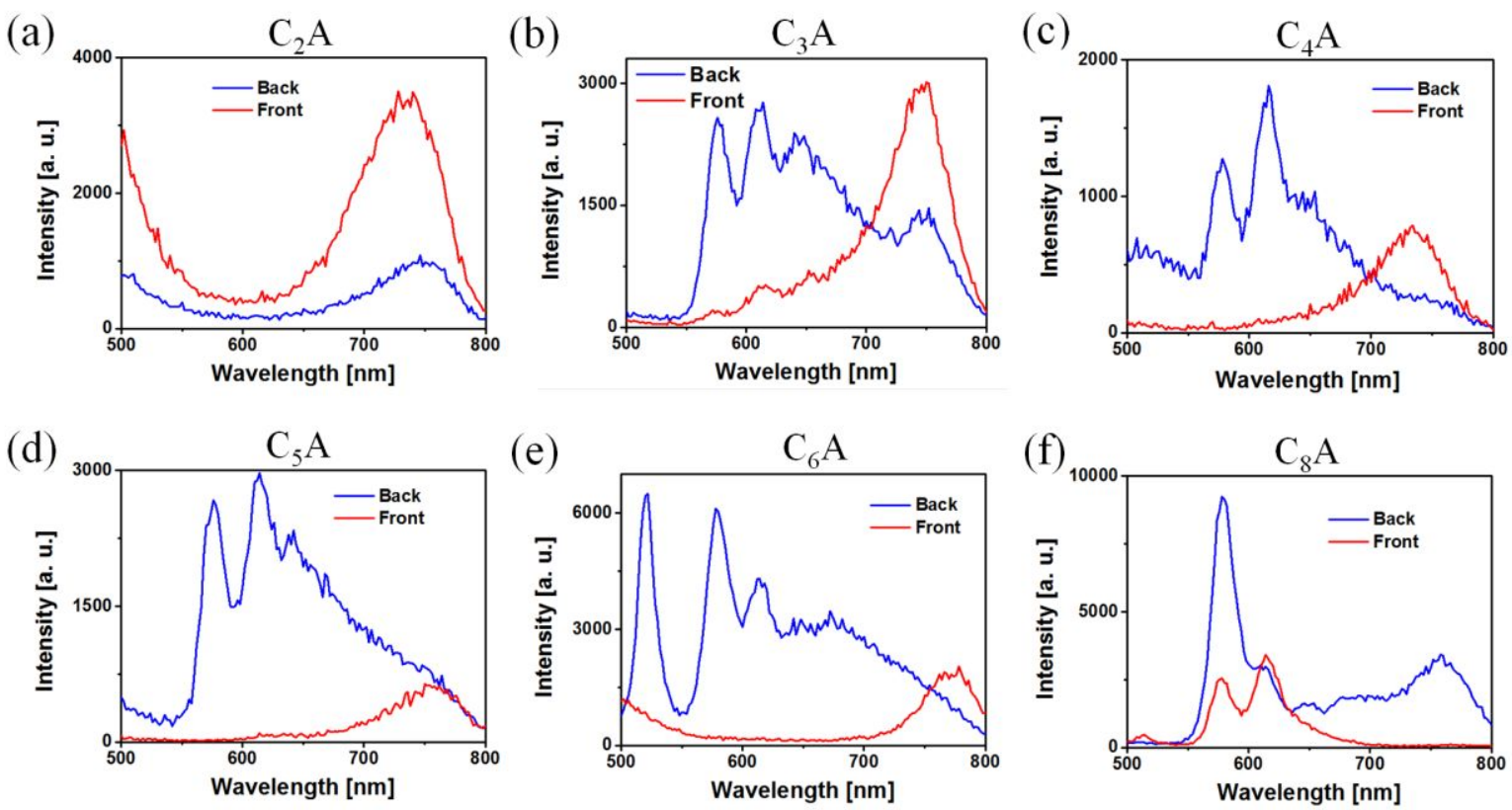

Figure S5. PL emission spectra of films drop-cast from solutions of $\left(\mathrm{C}_{m} \mathrm{~A}\right)_{2} \mathrm{MA}_{3} \mathrm{~Pb}_{4} \mathrm{I}_{13}$ in DMF, as a function of $m$. Samples were Glass/PEDOT:PSS/perovskite. Excitation and emission detection from either the perovskite (front) side or the glass (back) side. Excitation wavelength: $440 \mathrm{~nm}$.

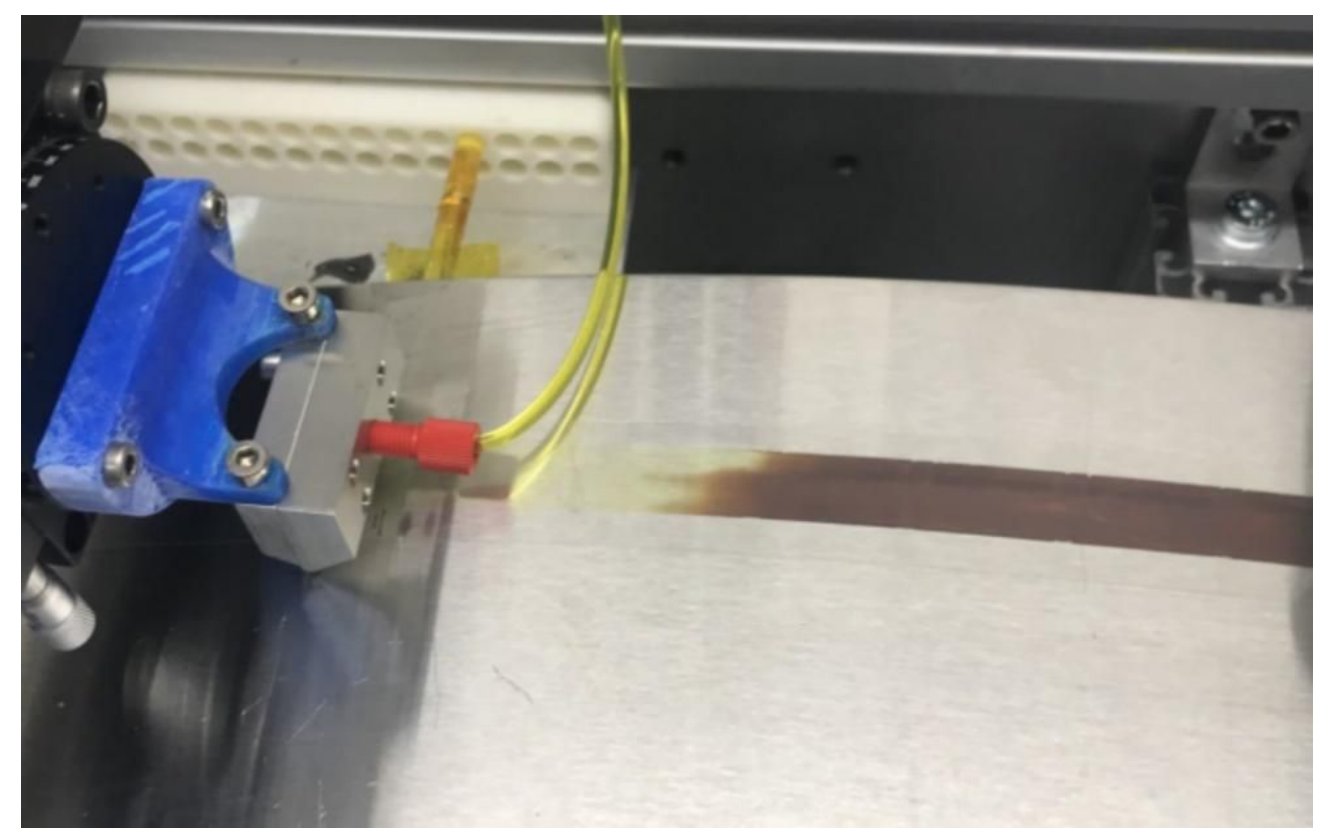

Figure S6. Photograph showing the drying of the R2R slot-die coated solution of $\left(\mathrm{C}_{4} \mathrm{~A}\right)_{2} \mathrm{MA}_{4} \mathrm{~Pb}_{5} \mathrm{I}_{16}$ on the $60{ }^{\circ} \mathrm{C}$ hot-plate. 
Table S1. Performance of solar cells comprising a layer drop-cast from $\left(\mathrm{C}_{m} \mathrm{~A}\right)_{2} \mathrm{MA}_{3} \mathrm{~Pb}_{4} \mathrm{I}_{13}$ solutions.

\begin{tabular}{lllll}
\hline$m$ & $\begin{array}{l}V_{\text {oc }} \\
{[\mathrm{V}]}\end{array}$ & $\begin{array}{l}J_{\mathrm{sc}} \\
{\left[\mathrm{mA} / \mathrm{cm}^{2}\right]}\end{array}$ & $\begin{array}{l}\mathrm{FF} \\
{[\%]}\end{array}$ & $\begin{array}{l}\mathrm{PCE}^{\mathrm{a}} \\
{[\%]}\end{array}$ \\
\hline 2 & 0.88 & -10.74 & 34.19 & $3.23(2.03 \pm 0.59)$ \\
3 & 1.16 & -17.85 & 62.86 & $13.01(12.32 \pm 0.54)$ \\
4 & 1.14 & -18.45 & 68.06 & $14.31(13.13 \pm 1.08)$ \\
5 & 1.08 & -16.61 & 65.33 & $11.72(10.97 \pm 0.93)$ \\
6 & 0.56 & -3.81 & 30.53 & $0.65(0.24 \pm 0.22)$ \\
\hline
\end{tabular}

aAverage PCE obtained from measurements of 10 cells. Standard deviations shown in parentheses.

Table S2. Performance of solar cells comprising a layer drop-cast from $\left(\mathrm{C}_{4} \mathrm{~A}\right)_{2} \mathrm{MA}_{n-1} \mathrm{~Pb}_{n} \mathrm{I}_{3 n+1}$ solutions.

\begin{tabular}{lllll}
\hline$n$ & $\begin{array}{l}V_{\text {oc }} \\
{[\mathrm{V}]}\end{array}$ & $\begin{array}{l}J_{\mathrm{sc}} \\
{\left[\mathrm{mA} / \mathrm{cm}^{2}\right]}\end{array}$ & $\begin{array}{l}\mathrm{FF} \\
{[\%]}\end{array}$ & $\begin{array}{l}\mathrm{PCE}^{\mathrm{a}} \\
{[\%]}\end{array}$ \\
\hline 1 & 0.26 & -0.1 & 28.74 & $0.01(0.01 \pm 0.01)$ \\
2 & -0.63 & 36.99 & $0.20(0.16 \pm 0.03)$ \\
3 & 0.86 & -12.39 & 63.10 & $7.97(7.01 \pm 0.86)$ \\
4 & 1.02 & -18.45 & 68.06 & $14.31(13.13 \pm 1.08)$ \\
5 & 1.14 & -19.18 & 70.22 & $15.08(14.61 \pm 0.30)$ \\
6 & 1.12 & -15.83 & 62.33 & $9.87(8.05 \pm 2.14)$ \\
8 & 1.00 & -10.9 & 36.49 & $3.18(2.07 \pm 1.02)$ \\
\hline
\end{tabular}

${ }^{a}$ Average PCE obtained from measurements of 10 cells. Standard deviations shown in parentheses. 
Table S3. Performance of solar cells made by using drop-casting (on glass substrate) and slot-die coating (on flexible substrate).

\begin{tabular}{lllll}
\hline Method & $V_{\mathrm{oc}}$ & $J_{\mathrm{sc}}$ & $\mathrm{FF}$ & $\mathrm{PCE}^{\mathrm{a}}$ \\
& {$[\mathrm{V}]$} & {$\left[\mathrm{mA} / \mathrm{cm}^{2}\right]$} & $\begin{array}{l}{[\%]} \\
{[\%]}\end{array}$ & \\
\hline Drop-casting & 1.12 & -19.18 & 70.22 & $15.08(14.61 \pm 0.30)$ \\
Slot-die coating & 1.08 & -15.58 & 52.02 & $8.75(8.36 \pm 0.65)$ \\
\hline
\end{tabular}

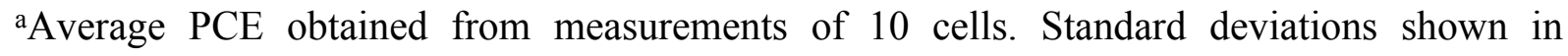
parentheses. 